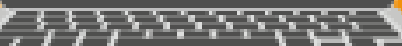

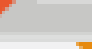

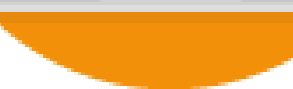

\title{
NARRATIVAS SOBRE CURRÍCULO E TECNOLOGIAS EM CLASSES HOSPITALARES
}

\author{
Adriana da Silva Ramos de Oliveira \\ Universidade Católica Dom Bosco-Brasil \\ Universidade Federal de Mato Grosso do Sul (UFMS)-Brasil \\ adrianaramosuniderp@gmail.com
}

Maria Cristina Lima Paniago

Universidade Católica Dom Bosco-Brasil

\section{RESUMO}

$\mathrm{O}$ artigo corresponde a reflexões de uma pesquisa de doutorado em andamento. O objetivo é apresentar narrativas sobre as práticas pedagógicas nos hospitais. Especificamente relatar sobre as necessidades de adaptações e flexibilizações curriculares para o ambiente hospitalar, apontar as possibilidades de utilização de tecnologias educacionais nesses espaços. A metodologia utilizada foi a pesquisa bibliográfica e de campo. Obteve-se como resultados que a pesquisa de campo possibilitou através do acesso aos documentos históricos conhecermos as práticas pedagógicas das classes hospitalares de Campo Grande/MS; que os espaços são equipados com tabletes, notebooks e que os professores fazem uso de tecnologias educacionais principalmente para atender aos que estão em leitos de isolamento.

Palavras-chave: Classes hospitalares, Currículo, Tecnologias.

\section{INTRODUÇÃO}

Atualmente toda criança e adolescente do nosso país tem direito a educação. Poucas pessoas sabem, mas esse direito deve ser garantido até mesmo em momentos em que seja necessária a hospitalização. Esse direito é valido em qualquer condição clínica, seja essa temporária ou permanente. Com isso, há muitos anos as classes hospitalares foram/são inseridas em hospitais modificando positivamente a rotina de inúmeras crianças e adolescentes enfermos.

Esse espaço rico em relações humanizadoras tem características únicas que não podem ser neutras dada as necessidades de práticas pedagógicas diferenciadas. Esse universo muito específico é foco de uma pesquisa de doutorado em desenvolvimento que retrata essa diversidade de experiência, situações, relações que estão atravessadas por um misto de 


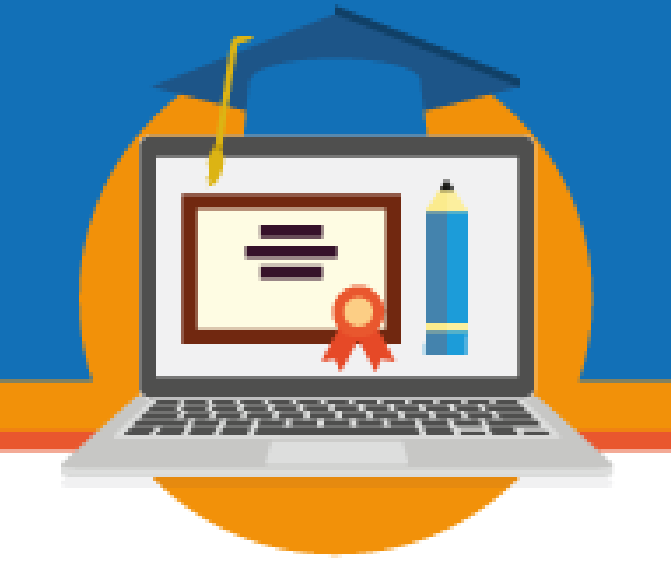

condições particulares como o adoecimento em si, o contexto hospitalar, a equipe médica, a equipe pedagógica, as relações com o aluno/paciente, com a família, o quadro clínico, o currículo, o ensino e a aprendizagem e os materiais específicos. Tudo isso nos direciona para outras Pedagogias, no caso, a que chamamos de Pedagogia Hospitalar.

Assim, no momento temos a intenção de apresentar no artigo algumas narrativas da pesquisa com base no levantamento bibliográfico e de campo realizado no primeiro semestre do ano de 2017. Aqui o assunto será apresentado em três tópicos: 1) Narrativas sobre práticas pedagógicas em hospitais, 2) Adaptações e flexibilizações curriculares para o ambiente hospitalar; 3) A utilização das tecnologias educacionais em classes hospitalares.

Todavia tivemos como objetivo descrever como são as práticas pedagógicas nos hospitais de Campo Grande/MS; especificamente apontar as necessidades de adaptações e flexibilizações curriculares dadas as particularidades envolvidas no ambiente hospitalar; apresentar as possibilidades de utilização das tecnologias educacionais nesses espaços.

Diante do exposto acima, o artigo está organizado em três tópicos: 1) Práticas pedagógicas nos hospitais; 2) Adaptações e flexibilizações curriculares para o ambiente hospitalar; 3) A utilização das tecnologias educacionais nas classes hospitalares. Primeiramente apresentaremos o contexto das práticas pedagógicas que são desenvolvidas nos hospitais de Campo Grande/MS conforme as recomendações do Ministério da Educação (MEC) e Ministério da Saúde (MS), em seguida as reflexões são a respeito das adaptações e flexibilizações curriculares para o ambiente hospitalar e, por fim, são apresentadas as possibilidades de utilização das tecnologias educacionais nas classes hospitalares.

\section{Narrativas sobre práticas pedagógicas em hospitais;}

Quando uma pessoa relata os fatos vividos por ela mesma, percebe-se que reconstrói a trajetória percorrida dando-lhe novos significados. Assim, a narrativa não é a verdade literal dos fatos, mas antes, é a representação que deles faz o sujeito e, dessa forma, pode ser transformadora da própria realidade. (CUNHA, 1997, p. 3). 


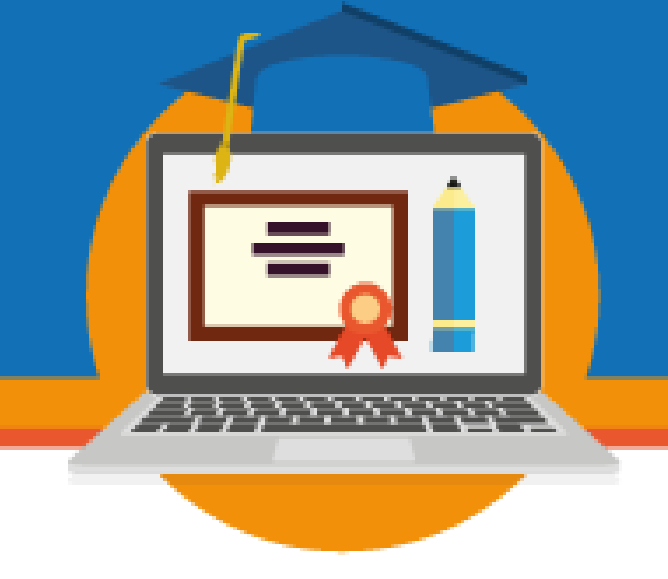

A partir da reflexão de Cunha (1997), precisamos ressaltar que apesar do intenso movimento em um hospital, em uma classe hospitalar os dias passam muito lentamente para todos os envolvidos, nesse momento transformar a própria realidade é uma necessidade para todos. É nesse ambiente complexo que diversos professores(as) trabalham diariamente tentando ultrapassar fronteiras, a saber

denomina-se classe hospitalar o atendimento pedagógico-educacional que ocorre em ambientes de tratamento de saúde, seja na circunstância de internação, como tradicionalmente conhecida, seja na circunstância do atendimento em hospital-dia e hospital-semana ou em serviços de atenção integral à saúde mental. (BRASIL, 2002, p. 13).

Podemos acrescentar, a partir da nossa imersão no campo, das narrativas dos(as) professores(as), das experiências acadêmicas, profissionais, pessoais, que o atendimento oferecido em classe hospitalar vai além das questões meramente pedagógico-educacional. Por esse motivo, a narrativa torna-se significativa para a apresentação do tema em questão. Para Cunha (1997, p. 2) "constantemente temos usado o expediente das narrativas, tanto em situações de pesquisa como de ensino e observando os processos vividos pelos envolvidos".

Desse modo, contextualizar práticas pedagógicas em hospitais é narrar múltiplas histórias, vivencias, acontecimentos, sentimentos que são muito positivos quando olhados a partir da perspectiva biofisiológica, energética, psicológica, social, espiritual, (GONZÁLEZ e GONZÁLEZ, 2007).

À medida que explicamos nossas próprias ações e os eventos humanos que acontecem em nossa volta, principalmente em termos de narrativa, história, drama, é concebível que nossa sensibilidade à narrativa constitua a principal ligação entre nosso próprio self e nosso sentido de outros no mundo social à nossa volta. (BRUNER, 1997, p. 74).

No Mato Grosso do Sul (MS), hoje as poucas classes hospitalares que temos possuem uma dinâmica de funcionamento próxima das escolas regulares, tem equipe pedagógica própria, professores lotados na educação infantil, ensino fundamental e médio, fisicamente as salas são equipadas com computadores, notebook, tabletes. É nesse contexto que estamos desenvolvendo 


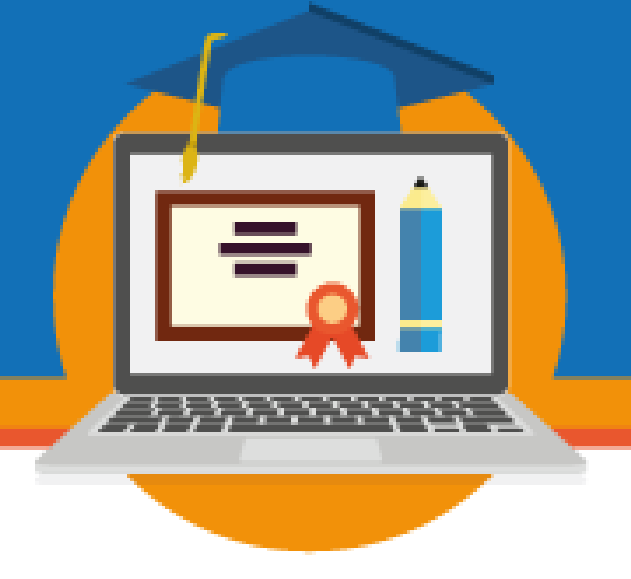

a pesquisa de doutoramento que, de modo específico, tem um olhar para a formação de professores (as) que trabalham em hospitais/classes hospitalares de Campo Grande (MS).

Com o desenvolvimento da pesquisa concordamos com o exposto em Cunha (1997, p. 2) que "as apreensões que constituem as narrativas dos sujeitos são a sua representação da realidade e, como tal, estão prenhes de significados e reinterpretações”. Desde que iniciamos a pesquisa percebemos que esses espaços são singulares e estão cheios de significados que vão além de questões apenas pedagógicas.

Apesar disso, ao fazermos a pesquisa bibliográfica identificamos que em nosso país/Estado pouco é publicado sobre prática pedagógica hospitalar, currículo para classes hospitalares e menos ainda sobre a formação de professores que atuam nesses espaços, apesar de constar nas Diretrizes Nacionais para a Educação Especial na Educação Básica

\begin{abstract}
Art. 13. Os sistemas de ensino, mediante ação integrada com os sistemas de saúde, devem organizar o atendimento educacional especializado a alunos impossibilitados de frequentar as aulas em razão de tratamento de saúde que implique internação hospitalar, atendimento ambulatorial ou permanência prolongada em domicílio. § 1o As classes hospitalares e o atendimento em ambiente domiciliar devem dar continuidade ao processo de desenvolvimento e ao processo de aprendizagem de alunos matriculados em escolas da Educação Básica, contribuindo para seu retorno e reintegração ao grupo escolar, e desenvolver currículo flexibilizado com crianças, jovens e adultos não matriculados no sistema educacional local, facilitando seu posterior acesso à escola regular. (BRASIL, 2001, p. 13).
\end{abstract}

A práticas pedagógicas em hospitais exige do(a) professor(a) conhecimento de diversos aspectos, próprios do universo complexo que é o hospital, que muitas vezes não é oferecido nos Projetos Políticos de Cursos (PPC), de alguns cursos de licenciaturas, estando presente muitas vezes em pós-graduações especificas. Além disso, é necessário conhecimentos sobre as questões físicas, psicológicas e sociais do adoecer, do estar doente, do lidar com o adoecido, assim como o luto constante devido as perdas e acima de tudo, saber lidar com os efeitos colaterais das medicações, exames, quadros clínicos que interferem no rendimento escolar.

É necessário ainda conhecimento dos aspectos legais, históricos da profissão, segurança do trabalho, o conhecimento do que é exercer a docência em um hospital com equipes de trabalhos multidisciplinares (saúde e educação), conhecer o que é, e como é ensinar uma 


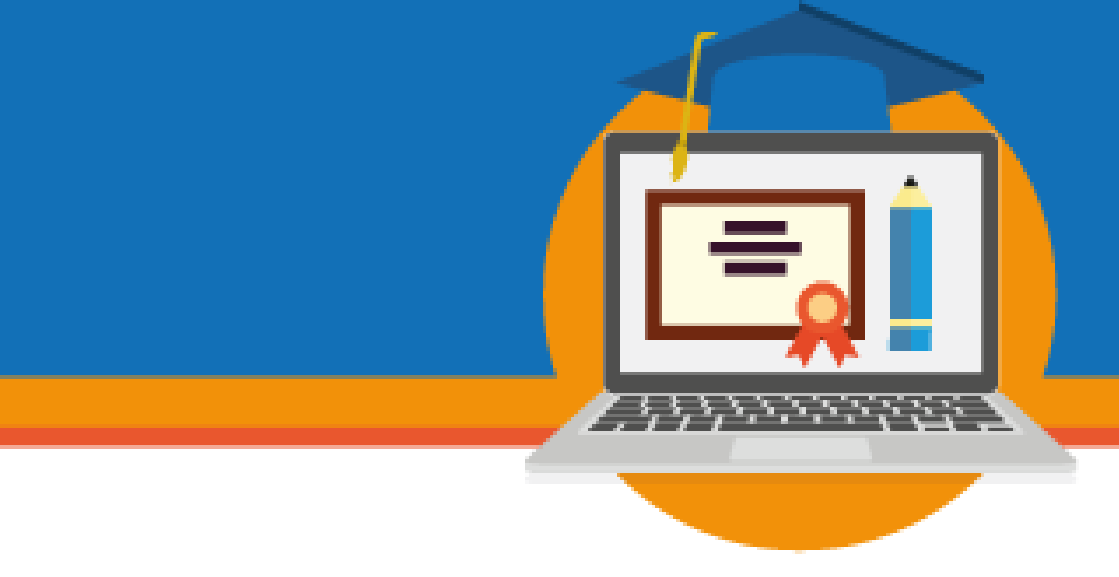

criança, um adolescente enfermo, quais são as práticas pedagógicas permitidas ou não, até mesmo os materiais didáticos que podem ser utilizados em cada ambiente (leito, enfermaria, no quarto de isolamento).

Ao fazermos a pesquisa de campo tivemos conhecimento que são poucas as classes hospitalares no MS, temos em Campo Grande (4), Corumbá (1) e Dourados (1). Na capital o trabalho está mais consolidado que no interior do Estado, é o que percebemos nas narrativas e em recortes de jornais da época que são guardados com muito cuidado pelas coordenadoras em uma das classes hospitalares visitadas.

Em um jornal, com marcas do tempo que se passou desde a sua publicação podemos constatar que a vinte e três anos existem professores(as) que desenvolvem práticas pedagógicas em hospitais da capital. São anos e anos de narrativas de humanização, dedicação, esperança, consta que

os pacientes internados em cinco unidades hospitalares de Campo Grande, Hospital Universitário, Regional, Santa Casa, São Julião e AACC (Associação dos Amigos das Crianças com Câncer), que por questões de tratamento de saúde encontram-se afastadas da escola, estão recebendo educação formal através da Secretaria de Educação do Estado. (OTA, VASCONCELOS, 2001, p. 4).

Ter acesso aos documentos de implantação das classes hospitalares em MS nos permitiu resgatar o passado e assim concordamos com Ferrer Cerveró (1995, p. 178) que a "historicidade dos fatos percorridos se converte em um elemento catártico de des-alienação individual e coletiva, que permite situar-se desde uma nova posição no mundo". Conforme mencionamos no início da seção, são poucas as publicações do MS que trazem informações sobre as classes hospitalares. Não foi localizada nenhuma publicação específica sobre a formação continuada de professores que atuam em classes hospitalares de MS até o momento. Esta é uma realidade preocupante e permite reflexões. Esse é um tema que precisa ter prioridade nos encaminhamentos da SED/MS. O tema que será apresentado a seguir mostrará justamente esse reflexo. 


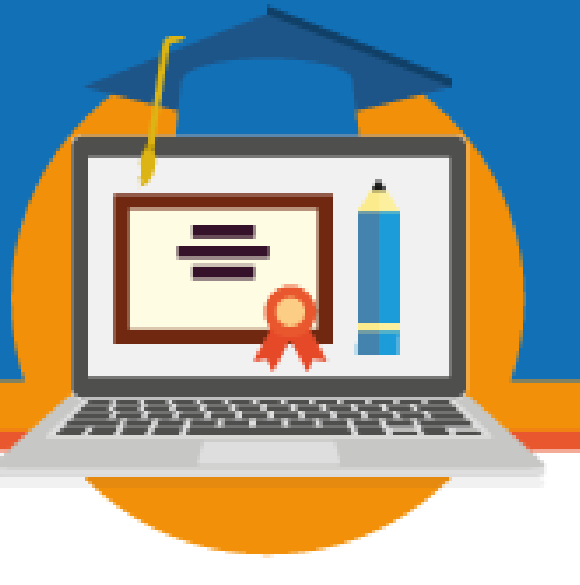

\section{Adaptações e flexibilizações curriculares para o ambiente hospitalar}

Quando pesquisamos sobre classes hospitalares, fica evidente que a legislação, e também as literaturas apontam que o caminho para a escolarização no ambiente hospitalar "requer-se medidas de flexibilização e dinamização do currículo para atender, efetivamente, às necessidades educacionais especiais" (BRASIL, 1998, p. 13). Adaptar e flexibilizar o currículo para o ambiente hospitalar, é uma necessidade visto que

a pessoa hospitalizada, o tratamento de saúde não envolve apenas os aspectos biológicos da tradicional assistência médica à enfermidade. A experiência de adoecimento e hospitalização implica mudar rotinas; separar-se de familiares, amigos e objetos significativos; sujeitar-se a procedimentos invasivos e dolorosos e, ainda, sofrer com a solidão e o medo da morte - uma realidade constante nos hospitais. Reorganizar a assistência hospitalar, para que dê conta desse conjunto de experiências, significa assegurar, entre outros cuidados, o acesso ao lazer, ao convívio com o meio externo, às informações sobre seu processo de adoecimento, cuidados terapêuticos e ao exercício intelectual. (BRASIL, 2002, p. 9-10).

No momento da escolarização no hospital, quando fazemos as adaptações e flexibilizações curriculares necessárias a cada criança e adolescente hospitalizado, damos a eles a oportunidade e o direito do exercício intelectual preconizado em toda referência bibliográfica sobre o tema, sendo assim "a forma pela qual cada aluno terá acesso ao currículo distingue-se pela singularidade" das suas condições físicas, emocionais, psíquicas (BRASIL, 2001, p. 26). Com isso, conseguimos adaptar metodologias, conteúdos, materiais e avaliações. Nas classes hospitalares de Campo Grande/MS, assim como em outros estados

o atendimento pedagógico deverá ser orientado pelo processo de desenvolvimento e construção do conhecimento correspondentes à educação básica, exercido numa ação integrada com os serviços de saúde. A oferta curricular ou didático-pedagógica deverá ser flexibilizada, de forma que contribua com a promoção de saúde e ao melhor retorno e/ou continuidade dos estudos pelos educandos envolvidos. (BRASIL, 2002, p. 17).

Para a criança e o adolescente hospitalizado, a possibilidade de estudar muitas vezes contribui para a melhoria do quadro clínico, ajuda na construção de uma rotina que é muito próxima da vida cotidiana, não interrompe a escolarização, oportuniza a socialização com 


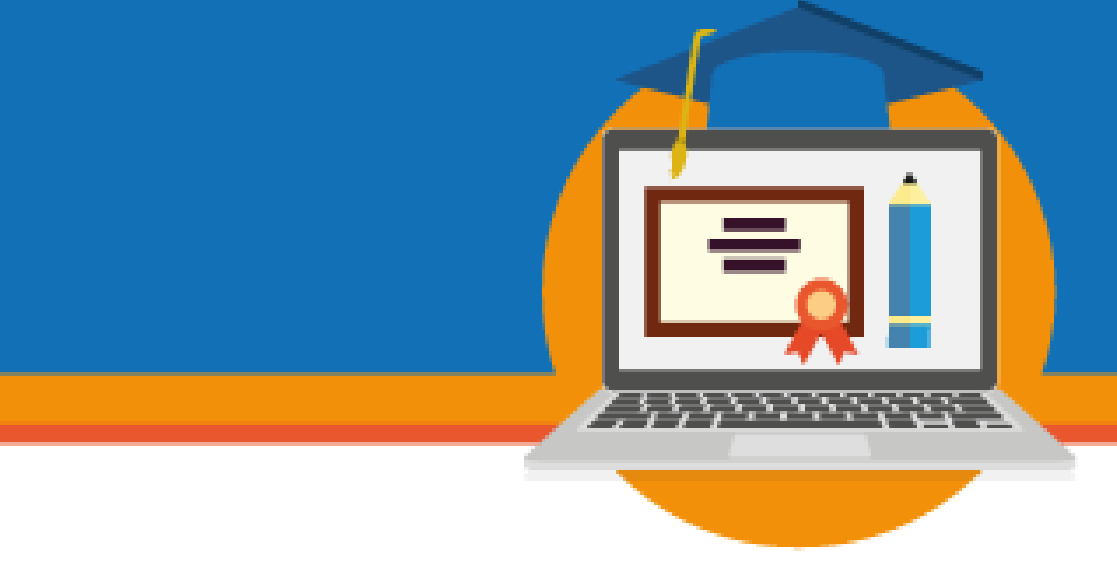

outras crianças hospitalizadas e ainda ajuda a minimizar fadigas. É nesse sentido, que as adaptações e flexibilizações curriculares são elaboradas, para que possam atender a essas diversidades e ainda diminuir atrasos no desenvolvimento em função da hospitalização.

Como no ensino regular, os currículos das classes hospitalares passam por processos constantes de tensões, revisões e adequações, pois, "atender a esse continuo de dificuldades requer respostas educativas adequadas, que abrangem graduais e progressivas adaptações de acesso [...] bem como adaptações de seus elementos" (BRASIL, 2001, p. 58). Desse modo, de forma dinâmica, o currículo vai sendo tramado a partir do diálogo (saúde, educação), dos sentidos, significados que deve ter a escolarização para os hospitalizados, sempre com foco de possibilitar o retorno à escola de origem antes da hospitalização.

É a partir desse currículo flexível, mas ao mesmo tempo compatível com o currículo da escola de origem para a qual irão retornar, que pode ser previsto a utilização de tecnologias educacionais nas classes hospitalares. Esse tema será apresentado no tópico a seguir.

\section{A utilização das tecnologias educacionais nas classes hospitalares}

Atualmente, através da Política Nacional de Tecnologia Educacional e do Regime Especial de Incentivo a Computadores para Uso Educacional (REICOMP), a inserção e a utilização de tecnologias educacionais nas escolas da educação básica passam a ser uma realidade cada vez mais constante.

No momento em que distintos artefatos tecnológicos começaram a entrar nos espaços educativos trazidos pelas mãos dos alunos ou pelo seu modo de pensar e agir inerente a um representante da geração digital evidenciou-se que as TDIC não mais ficariam confinadas a um espaço e tempo delimitado. (ALMEIDA; SILVA, 2011, p. 3).

Com o passar dos anos, muitos estudos foram feitos sobre educação e tecnologias "na escola, as tecnologias não ficam apenas isoladas em laboratórios e começam, pouco a pouco, a ser integradas às atividades de sala de aula e a outros espaços da escola ou fora dela para uso 


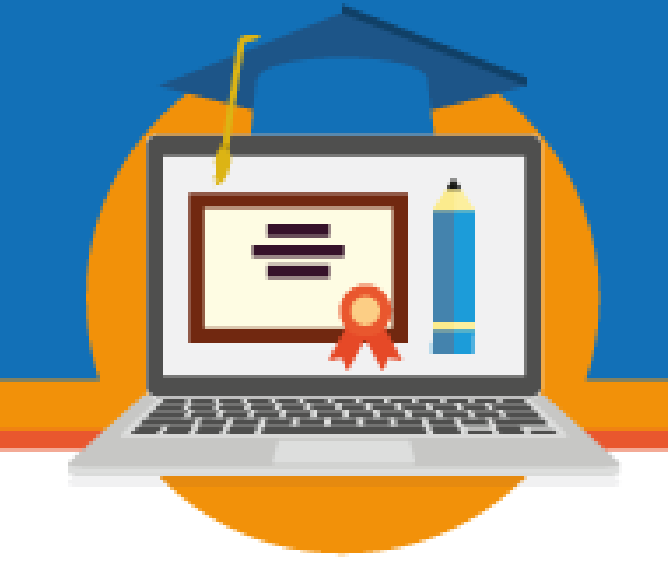

de acordo com necessidades e interesses evidenciados a qualquer momento" (ALMEIDA; SILVA, 2011, p. 3-4).

Como a classe hospitalar é uma modalidade da educação básica, ela é igualmente favorecida pela Política Nacional de Tecnologia Educacional e integra o uso das tecnologias em seus diferentes espaços. Atualmente, em Campo Grande/MS, todas as classes hospitalares são equipadas com computadores. Recentemente foram adquiridos mais cinco notebooks para atendimento pedagógico das crianças e adolescentes que ficam internados em leitos de isolamento. Esclarecemos que são diversas as condições clínicas que exigem essa retirada brusca do convívio social para o leito de isolamento, primando pela própria segurança do aluno paciente.

São infinitas as possibilidades de utilização das tecnologias educacionais nas classes hospitalares, mais os professores precisam ter conhecimento, apoio, formação. Como as classes hospitalares atendem alunos pacientes que estão matriculados no ensino fundamental e médio, quando fazemos pesquisas sobre a temática constata-se algumas publicações em diversas áreas do conhecimento como em Ciências Exatas, Biológicas, Sociais, Humanas, Linguística, Letras e Artes, onde alguns professores de diferentes regiões do país relatam experiências positivas em práticas pedagógicas em diversas disciplinas, que vão desde propostas lúdicas (inserção de jogos eletrônicos, passeios virtuais a museu de artes, construção de blogs, comunidades) até a utilização de software e programas para conteúdo específico. Nestas publicações ficam evidente que

o emprego das tecnologias na educação como coadjuvantes nos processos de ensino e aprendizagem para apoio às atividades ou, ainda, para motivação dos alunos, gradualmente dá lugar ao movimento de integração ao currículo do repertório de práticas sociais de alunos e professores típicos da cultura digital vivenciada no cotidiano (SILVA, 2010). (ALMEIDA; SILVA, 2011, p. 4).

Nota-se que o fato das crianças e adolescentes estarem hospitalizados, não faz com que deixem de ser nativos digitais ${ }^{1}$, que deixem de gostar de computadores, celulares, tablets. Nesse

${ }^{1} \mathrm{O}$ termo foi criado pelo norte-americano Marc Prensky, onde o autor considera aquele que nasceu e cresceu com as tecnologias digitais presentes em sua vivência. Pessoas que incorporam mídias digitais em seu cotidiano de 


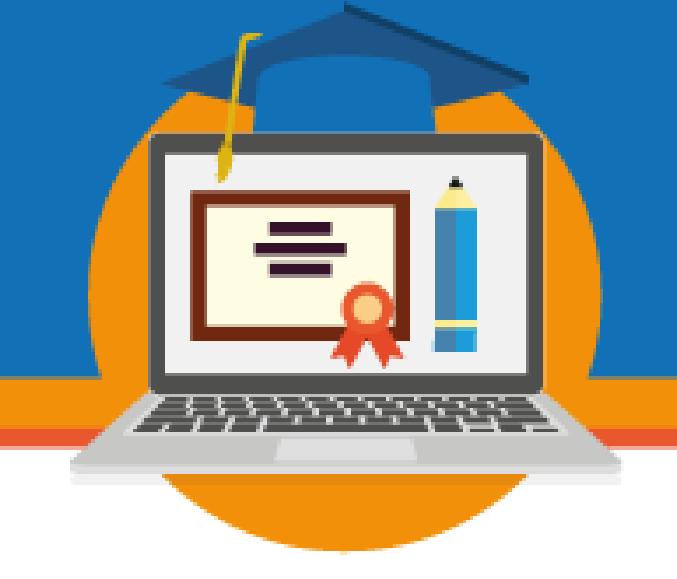

sentido, os professores que atuam nas classes hospitalares podem planejar qualquer atividade pedagógica utilizando esses recursos. A única recomendação é que essas atividades se adaptem ao ambiente que estejam hospitalizado, no caso aos leitos, enfermarias, quartos de isolamento, CTI, UTI ou até mesmo as brinquedotecas hospitalares,

\begin{abstract}
para tanto, é preciso que o educador possa apropriar-se da cultura digital e das propriedades intrínsecas das TDIC, "utilizá-las na própria aprendizagem e na prática pedagógica e refletir sobre por que e para que usar a tecnologia, como se dá esse uso e que contribuições ela pode trazer à aprendizagem e ao desenvolvimento do currículo" (ALMEIDA, 2010, p. 68). (ALMEIDA; SILVA, 2011, p. 6).
\end{abstract}

Essas reflexões sobre a inserção das tecnologias no currículo e nas práticas pedagógicas são para todos os professores da educação básica, assim como para as classes hospitalares, considerando as necessidades de o aluno paciente adquirir/construir saberes sistematizados. Estamos de acordo que

[...] o exercício de pensar o tempo, de pensar a técnica, de pensar o conhecimento enquanto se conhece, de pensar o quê das coisas, o para quê, o como, o em favor de quê, de quem, o contra quê, o contra quem são exigências fundamentais de uma educação democrática à altura dos desafios do nosso tempo (FREIRE, 2000, p. 46).

Não basta somente inserir as tecnologias em classes hospitalares para que elas se aproximem das escolas regulares. As crianças e adolescentes necessitam da utilização desses recursos conforme mencionado anteriormente. Diante do exposto, concordamos com Freire (2000), que esse é um desafio do nosso tempo, já que hoje a utilização de tecnologias faz parte do processo de educação formal das classes hospitalares.

\title{
Considerações Finais
}

Finalizamos sustentando que o assunto está longe de ser esgotado. É possível afirmar com a presente pesquisa que temos dois Ministérios (saúde e educação) que aprovam e

maneira significativa - tem novas expectativas em relação à aprendizagem, ao trabalho e à diversão. [...] mais importante: esperam se divertir ao brincar e experimentar com novas ideias e experiências. (GIBSON, 2010). 


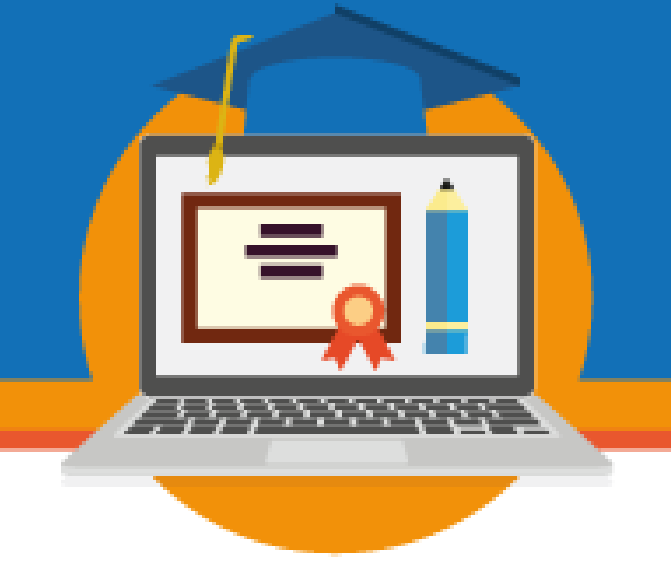

regularizam as atividades pedagógicas nos hospitais e as legislações que reconhecem o direito à escolarização no período de internação e reconhecem também que os professores atuantes em classes hospitalares precisam de formação continuada em função do exercício da profissão. Porém, temos constatado uma realidade contraditória no Estado de Mato Grosso do Sul.

Há um número muito pequeno de hospitais que oferecem classes hospitalares. Entre os que oferecem, há uma equipe reduzida de professores, o regime de trabalho é sem concurso público a 23 (vinte e três) anos, formação continuada esporádicas e mais uma infinidade de situações que legitimam falta de atenção por parte do poder público a essa modalidade tão importante.

A realidade mostra um distanciamento (direito sem ter direito). As crianças e adolescentes têm direito as classes hospitalares, mas a capital do Estado de Mato Grosso do Sul hoje oferece apenas quatro classes, sendo que a legislação menciona que toda unidade de saúde que tenha ala pediátrica tem a obrigação de oferecer atendimento pedagógico.

As adaptações e flexibilizações curriculares e a utilização das tecnologias educacionais devem fazer parte do cotidiano das classes hospitalares, mas a última formação continuada para os professores foi oferecida há oito anos. Essas e outras questões precisam ser analisadas a partir das suas raízes epistemológicas. 


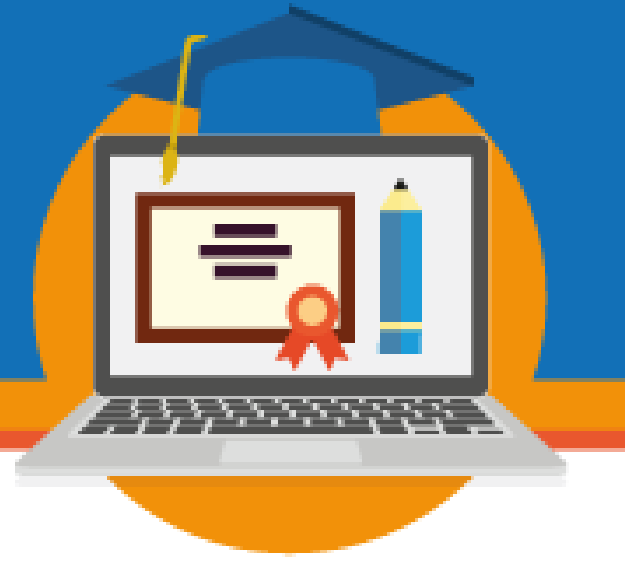

\section{REFERÊNCIAS}

ALMEIDA, Maria Elizabeth B. de; SILVA, Maria da Graça Moreira da. Currículo, tecnologia e cultura digital: espaços e tempos de web currículo. Revista e-curriculum, São Paulo, v.7 n.1 Abril/2011. Disponível em: < http://revistas.pucsp.br/index.php/curriculum>. Acesso em: 30 ago.2016.

BRASIL. Constituição (1988). Diário Oficial da União. Brasília, DF, 05 out. 1988.

, Estatuto da Criança e do Adolescente. Lei Federal 8.069 de 13 de julho de 1990. São Paulo, 1995b.

. Lei de Diretrizes e Bases da Educação Nacional. Lei n. ${ }^{\circ} 9394$ de 20 de dezembro de 1996. Brasília: Imprensa Oficial, 1996.

. Ministério da Educação. Resolução CNE/CEB N² 2, de 11 de setembro de 2001. Institui Diretrizes Nacionais para a Educação Especial na Educação Básica. MEC/SEESP, 2001.

BRASIL. Ministério da Educação. Classe hospitalar e atendimento pedagógico domiciliar: estratégias e orientações. / Secretaria de Educação Especial. Brasília: MEC; SEESP, 2002.

BRASIL. Ministério da Educação. Classe hospitalar e atendimento pedagógico domiciliar: estratégias e orientações. Secretaria de Educação Especial. Brasília: MEC; SEESP, 2002.

. Ministério da Educação. Resolução CNE/CEB 2/2001 de 11 de setembro de 2001. Institui Diretrizes Nacionais para a Educação Especial na Educação Básica. Diário Oficial da União, Brasília, 14 set. 2001. Seção 1E, p. 39-40.

. Secretaria de Educação Fundamental. Parâmetros curriculares nacionais:

Adaptações Curriculares. Secretaria de Educação Especial. Brasília: MEC /SEF/SEESP, 1998. Disponível em: <http://www.conteudoescola.com.br/pcn-esp.pdf>. Acesso em: 05 nov. 2013.

BEHRENS, Marilda Aparecida. Caminhos da escolarização hospitalar para uma visão da complexidade. In: MATOS, Elizete Lúcia Moreira Matos (ORG.). Escolarização hospitalar: educação e saúde de mãos dadas para humaniza. Petrópolis/RJ: Vozes, 2009. p. 09-20.

BRUNER, Jerome S. Atos de significação. Porto Alegre, RS: Artes Médicas, 1997.

CASTRO. Marleisa Zanella de. Escolarização hospitalar: desafios e perspectivas. In:

MATOS, Elizete Lúcia Moreira Matos (ORG.). Escolarização hospitalar: educação e saúde de mãos dadas para humaniza. Petrópolis/RJ: Vozes, 2009. p. 35-51. 


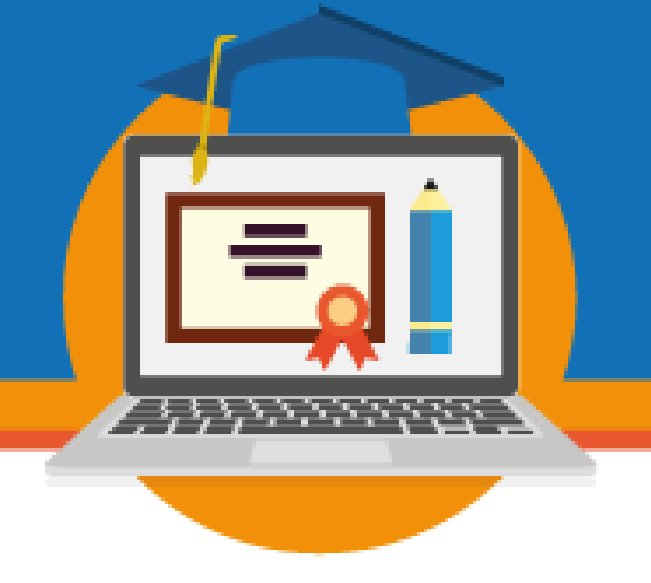

CUNHA, Maria Isabel da. Conta-me agora!: as narrativas como alternativas pedagógicas na pesquisa e no ensino. Revista da Faculdade de Educação, v. 23, n. 1-2, 1997.

FREIRE, Paulo. Desafios da educação de adultos ante a nova reestruturação tecnológica. Editora UNESP, 2000. . In: Pedagogia da indignação: cartas pedagógicas e outros escritos. São Paulo:

FERRER CERVERÓ, Virgínia. La crítica como narrativa de las crisis de formación. In: LARROSA, Jorge. Déjame que te cuente. Barcelona: Editorial Laertes, 1995.

GIBSON, David. Prefacio. In: MATTAR, João. Games em educação: como os nativos digitais aprendem. São Paulo: Pearson Printice Hall, 2010.

GONZÁLEZ, Eugenio; GONZÁLEZ, Crescenciana. Classes hospitalares. In: GONZÁLEZ, Eugenio (COORD.); ARRILLAGA, María... [et al.]. Necessidades educacionais específicas: intervenção psicoeducacional. (Trad. D. V. de Moraes). Porto Alegre: Artmed, p. 344-369, 2007.

OTA, Neiba Yukime; VASCONCELOS Marycleide. Da redação Neiba, fotos Marycleide. Inovações pedagógicas. Classes hospitalares. Ensino público chega aos hospitais. Educação do Estado promove a inclusão escolar de crianças submetidas a longos tratamentos de saúde. Jornal Folha do povo. Campo Grande, quinta-feira, 05 de julho de 2001, p. 4.

VIEGAS, Drauzio; LARANJEIRA, Marisa Silva. Brinquedoteca terapêutica no âmbito hospitalar. In: ASSUMPÇÃO JUNIOR, Francisco Baptista; KUCZYNNSKI, Everlin (ORG.). Qualidade de vida na infância e na adolescência: orientações para pediatra e profissionais da saúde mental. Porto Alegre: Artmed, 2010. p. 387-396. 